\title{
BMJ Open Modelling the household cost of paediatric malaria treatment in a rural county in Kenya: do non-user fee payments matter? A partial cost of illness analysis
}

Maurice Onditi Kodhiambo (D) , Julius Otieno Oyugi, ${ }^{2}$ Beatrice Kagai Amugune ${ }^{3}$

To cite: Kodhiambo MO, Oyugi J0, Amugune BK. Modelling the household cost of paediatric malaria treatment in a rural county in Kenya: do non-user fee payments matter? A partial cost of illness analysis. BMJ Open 2020;10:e033192. doi:10.1136/ bmjopen-2019-033192

- Prepublication history for this paper is available online. To view these files, please visit the journal online (http://dx.doi. org/10.1136/bmjopen-2019033192).

Received 24 July 2019 Revised 14 February 2020 Accepted 19 February 2020

D) Check for updates

(c) Author(s) (or their employer(s)) 2020. Re-use permitted under CC BY-NC. No commercial re-use. See rights and permissions. Published by BMJ.

${ }^{1}$ Pharmacy, Kenyatta University, Nairobi, Kenya

${ }^{2}$ Medical Microbiology,

University of Nairobi, Nairobi, Kenya

${ }^{3}$ Pharmaceutical Chemistry, University of Nairobi, Nairobi, Kenya

Correspondence to

Dr Maurice Onditi Kodhiambo; kodhiambo.maurice@ku.ac.ke

\section{ABSTRACT}

Objective The objective of this study was to develop an econometric model for the cost of treatment of paediatric malaria from a patient perspective in a resource scarce rural setting of Homa Bay County, Kenya. We sought to investigate the main contributors as well as the contribution of non-user fee payments to the total household cost of care. Costs were measured from a patient perspective.

Design The study was conducted as a health facility based cross sectional survey targeting paediatric patients. Setting The study was conducted in 13 health facilities ranging from level II to level V in Homa Bay County which is in the Eastern shores of Lake Victoria, Kenya. This is a malaria endemic area.

Participants We enrolled 254 inpatient children (139 males and 115 females) all of whom participated up to the end of this study.

Primary outcome measure The primary outcome measure was the cost of pediatric malaria care borne by the patient. This was measured by asking exiting caregivers to estimate the cost of various items contributing to their total expenditure on care seeking. Results A total of 254 respondents who consented from 13 public government health facilities were interviewed. Age, number of days spent at the health facility, being treated at a level $\mathrm{V}$ facility, medical officer prescribing and seeking initial treatment from a retail shop were found significant predictors of cost.

Conclusion Higher level health facilities in Homa Bay County, where the more specialised medical workers are stationed, are more costly hence barring the poorest from obtaining quality paediatric malaria care from here. Waiving user fees alone may not be sufficient to guarantee access to care by patients due to unofficial fees and nonuser fees expenditures.

\section{INTRODUCTION}

Cost of healthcare services in sub-Saharan Africa is a major impediment to attainment of Universal Health Coverage. ${ }^{1}$ Malaria is a major cause of paediatric morbidity and mortality in this part of the world. ${ }^{23}$ The burden of

\section{Strengths and limitations of this study}

- The study includes both direct and indirect costs including opportunity cost of time lost for caring for the patient.

- We used robust statistical analysis; stepwise regression analysis was chosen to take care of any possible confounders to the study findings.

- The study was conducted from a patient perspective thus restricting interpretation of the findings to the patient perspective only.

- The data were collected solely through exit interviews of caregivers.

- The study was conducted in one county and the findings may therefore not be generalisable to all counties in Kenya due to geographic and socioeconomic variations.

malaria treatment on households is felt most among poor rural populations. ${ }^{4}$ Understanding the cost drivers for the treatment of paediatric malaria is important for devising strategies for optimising such costs. Few cost-modelling studies on paediatric malaria treatment in resource scarce settings, from a patient perspective, have been performed as is the case in this study. Most models have not included costs ingredients such as forgone earnings and cost of transportation to and from the heath facility. ${ }^{5}$ When free treatment policy for malaria in children under the age of 5 years was introduced in Kenya in the year 2005 , it was expected that such a shift would improve financial access to treatment by the poorest patients. This assumption however did not include non-user fee payments and other intangible costs that have been shown to be significantly associated with the risk of catastrophic household health expenditure. ${ }^{6}$ There have however been reports of several unofficial user fees being charged for 
paediatric malaria treatment despite their official abolition. ${ }^{7}$ This necessitates costing malaria treatment from a patient perspective in order to capture all costs incurred by the patient in the process of care seeking. The objective of this study was to develop a cost model for the treatment of paediatric malaria from a patient perspective in the resource scarce setting of Homa Bay County, Kenya.

\section{METHODS}

\section{Study setting}

Kenya is classified by the World Bank as a lower middleincome country ${ }^{8}$ with the under-five mortality rate at 45.6 per 1000 live births. ${ }^{9}$ Homa Bay County is a rural county with a predominantly peasant economy with poverty levels above the national average and some of the poorest child health indicators in the Kenya. In 2016, the county under-five mortality was 130 per 1000 live births. ${ }^{10}$ The Kenya Demographic and Health Survey 2014 also indicated that most residents of Homa Bay County lie in the lowest wealth quintile with an unfavourable Gini coefficient. These are economic indicators that may demonstrate that the average income of the residents is low. The county is located in the Eastern shores of Lake Victoria hence has climatic conditions that favour malaria endemicity, with pregnant women and children bearing the greatest burden of the disease. The prevalence of malaria in Homa Bay County, as of 2016, was 58820 per 100000 persons, which was more than double the national prevalence of 20252 per 100000 persons at that time (10). Malaria incidence usually peaks in Kenya around September to October rainy season which coincides with the time the study was conducted.

\section{Study design}

The study was conducted as a cross-sectional survey. This design was considered appropriate since it was strategic and affordable to collect all the data from the patients in one encounter at the end of the treatment process. Both the exposures and outcome were examined at the same time.

\section{Costing approach}

Costing was conducted from a patient perspective. The total costs were summed up from component expenditures incurred per category in the process of procuring care for the child with malaria as reported by the caregiver. In this study, the costing was computed to include all user fees and non-user fee monetary expenditures incurred by the caregiver in the process of seeking care for the sick child.

\section{Target population}

The target population comprised all children below 13 years exiting government health facilities in Homa Bay County after treatment for malaria during the period of study. Children below the age of 13 years were targeted because they tend to depend wholly on their parents or

\begin{tabular}{|c|c|c|}
\hline Facility level & Basis & Services offered \\
\hline Level I & Community & $\begin{array}{l}\text { A range of preventive and curative } \\
\text { services with a focus on primary } \\
\text { care services. }\end{array}$ \\
\hline Level II & Dispensaries & $\begin{array}{l}\text { Management of common illnesses } \\
\text { in the specific region }\end{array}$ \\
\hline Level III & Health centres & $\begin{array}{l}\text { Formal immunisation programs, } \\
\text { HIV testing and referral }\end{array}$ \\
\hline Level IV & $\begin{array}{l}\text { District referral } \\
\text { hospitals }\end{array}$ & $\begin{array}{l}\text { Antenatal care and routine } \\
\text { birthing services, HIV/AIDS care } \\
(96 \%) \text {, paediatric services (93\%) } \\
\text { and emergency obstetric care } \\
\text { (EmOC) }(78 \%) .\end{array}$ \\
\hline Level V & $\begin{array}{l}\text { Provincial referral } \\
\text { hospitals }\end{array}$ & $\begin{array}{l}\text { Surgical services, internal } \\
\text { medicine and specialty services } \\
\text { such as emergency EmOC } \\
\text { and anesthesiology but less } \\
\text { extensive as the National } \\
\text { Referral Hospitals. }\end{array}$ \\
\hline Level VI & $\begin{array}{l}\text { National referral } \\
\text { hospitals }\end{array}$ & $\begin{array}{l}\text { Surgical services, internal medicine } \\
\text { and specialty services such as } \\
\text { EmOC and anesthesiology }\end{array}$ \\
\hline
\end{tabular}

Source: Ministry of Health, 2017: The Healthcare system in Kenya and Kenyan healthcare sector: market study report

guardians for health seeking decisions since they are not yet independent financially or socially.

\section{Sampling}

The sample size was based on the Melody study ${ }^{11}$ which recommends that for cost outcomes, a sample size of approximately 200 would be required to generate a $95 \%$ CI precise to within $\pm 10 \%$ of the mean. A multistage sampling approach was adopted. First, the county was divided into eight zones; the eight subcounties. The health facilities were then stratified based on service provision levels (level II to level V, table 1). The county had neither a level I nor a VI facility and only one level $\mathrm{V}$ facility at the time of data collection. The level V facility was purposively included in the sample. Therefore, actual facility sampling was done only for levels II, III and IV facilities. A total of 13 facilities were sampled as shown in table 2. From each facility, approximately 20 in-patients were sampled using the systematic random sampling approach where every other paediatric patient exiting after treatment for malaria was approached by the research assistant for recruitment. This process was repeated on daily basis until the targeted sample size of 254 participants was met.

Table 2 Number of health facilities and participants sampled in the study

\begin{tabular}{lrrrrr}
\hline Facility level & II & III & IV & V & Total \\
\hline Number of facilities & 13 & 9 & 12 & 1 & 35 \\
Number of facilities sampled & 4 & 3 & 5 & 1 & 13 \\
Number of in-patients sampled & 68 & 54 & 100 & 32 & 254 \\
\hline
\end{tabular}




\section{Recruitment of study participants}

A research assistant approached a caregiver of an in-patient who had just been treated for malaria at the time of exit. This was followed by self-introduction after which the caregiver was requested to read the consent explanation (in a language they best understood- English, Swahili or Luo) and consider consenting.

\section{Data collection}

Data on contributors to cost as well as cost of paediatric malaria treatment was collected from August 2016 to November 2016 by use of a structured exit interview guide on consented participants. This period was selected because malaria infections in the region usually peak during rainy seasons of September to October. Both direct costs such as out of pocket payments and cost of medicines purchased as well as indirect costs such as transport, food, waiting time and opportunity cost incurred while taking care of the sick child were measured in Kenya shillings but reported in US\$ (100 K.Shs=US\$1) .

The interviewers were trained to probe opportunity cost borne by caregivers in the process of seeking healthcare for the sick child by asking them to state their occupation. From this, the approximate forgone benefit was estimated to triangulate the information gathered from their response to the direct questions posed to the caregiver about their estimated opportunity cost.

\section{Quality assurance}

Data collectors were trained for 2 days on the survey tool as well as the procedure in a classroom setting and then practised in the pre-test health facility outside the datacollection area (Migori County). Data-collection instruments were examined by supervisors and other experts to ascertain their quality and validity.

\section{Data analysis}

Data was checked for completeness, cleaned, sorted and coded. This was followed by data entry into excel (2016) spreadsheet in readiness for analysis by use of the $\mathrm{R}$ statistical software to compute descriptive statistics on cost of treatment. The cost of treatment was then further modelled on R (Studio) statistical package using a stepwise multiple linear regression approach.

\section{Patient and public involvement}

Given that there was no funding for this study, no funds or time was allocated for patient or public involvement. We were therefore unable to involve patients. However, we plan to invite representatives of the public to help us write a plain language summary for further dissemination of the results.

\section{RESULTS}

The survey was conducted across various health facilities ranging from level II to level $\mathrm{V}$. Most of the participating children, $47.6 \%$ (121), had been treated in level IV facilities. Level II facilities had 26.8\% (68) of the children; level III had 21.3\% (54) and level V had 4.3\% (11). Most participants, $55.5 \%$ (141), were 4-6 years old. Male children were $54.7 \%$ (139) while females were $45.3 \%$ (115). Most of the participants, $62.6 \%$ (159), travelled for $2-5 \mathrm{~km}$ to reach the health facility using mainly a motorcycle as the preferred means of transport $66.1 \%$ (168). After reaching the hospital, most of them, $72 \%$ (183), waited for about 1 hour to be served while $18.1 \%$ (46) were attended to within $30 \mathrm{~min}$. Medical officers, $46.5 \%$ (118) were the most common prescribers followed by clinical officers at $35.8 \%$ (91). Nurses prescribed for $17.7 \%$ (45) of the respondents. Most caregiver-respondents, $70 \%$ (178), stayed in the hospital with their children for 2 days or less with most of them, $61.8 \%$ (157), describing the condition of their children at admission as not very sick. Most of the participants $48 \%$ (122) first sought medical care in a community pharmacy outlet before proceeding to a government health facility. Table 3 is a summary of the baseline characteristics of the study participants.

\section{Cost drivers for the treatment of paediatric malaria in Homa Bay County}

The individual patient-reported costs per category were analysed and summarised as in table 4 .

\section{Modeling the cost of treating paediatric malaria}

The model representing the cost of treating paediatric malaria in Homa Bay County was developed by use of stepwise multiple linear regression analysis of the costing data collected from the exit interviews. The full model was first formulated as shown in table 5 followed by a reduced model after bootstrapping regression shown in table 6 .

A stepwise multiple linear regression was then performed to select the variables that contribute most meaningfully to the model. After this stepwise process, the variables that were isolated as mostly contributing to the model were age, facility levels, days of stay in the facility and prescriber. However, the statistically significant variables were days of stay in the facility ( $\mathrm{t}$ value $=4.10$, $\mathrm{p}$ value $<0.001$ ) and being treated at level IV and V facilities ( $\mathrm{t}$ value $=2.3$, $p$ value $<0.05$ ) .

From the obtained model, for every additional year of age, the total cost of care increased by US $\$ 0.82(95 \%$ $\mathrm{CI}=-0.05$ to 1.71$)$. Compared with level II facilities, the total cost of care was more expensive by US $\$ 14(95 \%$ $\mathrm{CI}=3.25$ to 24.78 ) in the level $\mathrm{V}$ facilities. For every additional day spent in the facility, the total cost of care increased by US $\$ 2.35$ (95\% CI=1.23 to 3.48 ) shillings. Being prescribed medicines by a clinical officer led to the total cost being lower by US $\$ 7.5$ (95\% CI $=3.17$ to 11.76) compared with prescription by a medical officer. The unadjusted coefficient of determination, $\mathrm{R}^{2}$, of the reduced model was $38 \%$ and the adjusted $\mathrm{R}^{2}$ was $33 \%$. This means that $33 \%$ of the relationship between cost variables and total cost as captured in this model is explained by the model and not random chance. This model thus explains $33 \%$ of the variation in costs. From the variables 
Table 3 Sociodemographic characteristics of study participants

\begin{tabular}{lcc}
\hline Factor & $\begin{array}{l}\text { Number of } \\
\text { children }\end{array}$ & $\%$ \\
\hline Facility level & & \\
\hline Level II & 68 & 26.8 \\
\hline Level III & 54 & 21.3 \\
\hline Level IV & 121 & 47.3 \\
\hline Level V & 11 & 4.4 \\
\hline Age of child (years) & & \\
\hline$<1$ & 11 & 4.3 \\
\hline $1-3$ & 74 & 29.1 \\
\hline $4-6$ & 141 & 55.5 \\
\hline $7-9$ & 22 & 8.7 \\
\hline $10+$ & 6 & 2.4 \\
\hline Sex of child & & \\
\hline Male & 139 & 54.7 \\
\hline Female & 115 & 45.3 \\
\hline Distance to health facility $(\mathrm{km})$ & & \\
\hline$<1$ & 40 & 15.7 \\
\hline $2-5$ & 159 & 62.6 \\
\hline $5-10$ & 50 & 19.7 \\
\hline$>10$ & 5 & 2 \\
\hline
\end{tabular}

Mode of transport to health facility

\begin{tabular}{|lrc|}
\hline Ambulance & 2 & 0.8 \\
\hline Bicycle & 13 & 5.1 \\
\hline Motorcycle & 168 & 66.1 \\
\hline On foot & 55 & 21.7 \\
\hline Private vehicle & 4 & 1.6 \\
\hline Public service vehicle & 12 & 4.7 \\
\hline $\begin{array}{l}\text { Waiting time before initial } \\
\text { treatment }\end{array}$ & \\
\hline$<30$ min & 46 & 18.1 \\
\hline 1 hour & 183 & 72 \\
\hline 2hours & 10 & 3.9 \\
\hline 3hours & 7 & 2.8 \\
\hline 3+ hours & 8 & 3.2 \\
\hline Prescriber & & \\
\hline Clinical officer & 91 & 35.8 \\
\hline Medical officer & 118 & 46.5 \\
\hline Nurse & 45 & 17.7 \\
\hline Days of stay at the facility & & \\
\hline $1-2$ & 170 & 66.93 \\
\hline $3-5$ & 38 & 15 \\
\hline $6-10$ & 38 & 15 \\
\hline $10+$ & 8 & 3.1 \\
\hline
\end{tabular}

Continued
Table 3 Continued

\begin{tabular}{lcc}
\hline Factor & $\begin{array}{l}\text { Number of } \\
\text { children }\end{array}$ & $\%$ \\
\hline $\begin{array}{l}\text { Caregiver reported severity of } \\
\text { Illness at admission }\end{array}$ & & \\
$\quad$ Not very sick & 157 & 61.8 \\
\hline$\quad$ Very sick & 97 & 38.2 \\
\hline $\begin{array}{l}\text { Initial treatment site } \\
\text { Community pharmacy outlet }\end{array}$ & 112 & 48.00 \\
\hline Dispensary (Level II) & 39 & 15.40 \\
\hline Government hospital & 36 & 14.20 \\
\hline Private hospital & 36 & 14.20 \\
\hline Religious leader & 16 & 6.30 \\
\hline Retail shop & 5 & 2.00 \\
\hline
\end{tabular}

in the reduced model, a regression equation was developed and summarised as follows.

\section{The multiple linear regression equation}

The econometric cost model for treating paediatric malaria in Homa Bay County generated from our data was represented by the generic equation given by:

$\mathrm{TC}=\beta 1$ Age $-\beta 2$ Level $3-\beta 3$ Level $4+\beta 4$ Level $5+\beta 5$

Days of stay $+\beta 6$ MO $+\beta 7$ Nurse $+€$

where

TC=total cost;

Level 3=treated at a level three health facility;

Level $4=$ treated at a level four health facility;

Level $\mathbf{5}=$ treated at a level five health facility;

Days of stay =number of days the respondent stays in the facility;

$\boldsymbol{\epsilon}=$ error term.

On substitution of the values of the coefficients, the final regression equation is

Total Household Cost $=3.36 *$ Level III $+5.87 *$ Level IV $+20.63 *$ Level V+23.83*Days of stay $+6.98 *$ Medical Officer+2.73*Nurse $+€$

\section{DISCUSSION}

This study was conducted in Homa Bay County which is in rural Western Kenya. The findings may therefore not be generalisable to other parts of the country. Costing was performed from a patient perspective. The patient perspective was considered the most appropriate because the survey focused on the individual patients at the point of exiting the process of care. The findings can therefore only be interpreted from this perspective. The median total cost (US\$) was 6.5 with a mean of 10 and a range of 1.4-65. This was lower than those reported from a study in Zambia where the average cost was 32 for uncomplicated and US $\$ 77$ for severe complicated malaria ${ }^{12}$ and from an earlier Kenyan Study with an average cost of US $\$ 96 .{ }^{13}$

Non-user fees such as cost of transportation and food were almost double the user fees, indicating that such 
Table 4 Patient reported costs of treating paediatric malaria in Homa Bay County

\section{Cost of treatment (US\$)}

\begin{tabular}{llcll} 
& Mean & Median & Minimum & Maximum \\
\cline { 2 - 5 } & 0.81 & 0.50 & 0 & 20 \\
Transport & 2.29 & 2.00 & 0.20 & 18 \\
Food & 5.56 & 3.25 & 1 & 50 \\
Value of time used for seeking care & 1.38 & 12 & 0 & 50 \\
Direct payment & & &
\end{tabular}

costs of care could be a major barrier to accessing care in this rural County even though official user fees for paediatric malaria were abolished by the government. It also shows that some facilities still charged unofficial user fees thus increasing the barrier to access. These findings concur with those from a study in Bolivia which indicated

Table 5 Full model of the cost of treatment of paediatric malaria

Full model

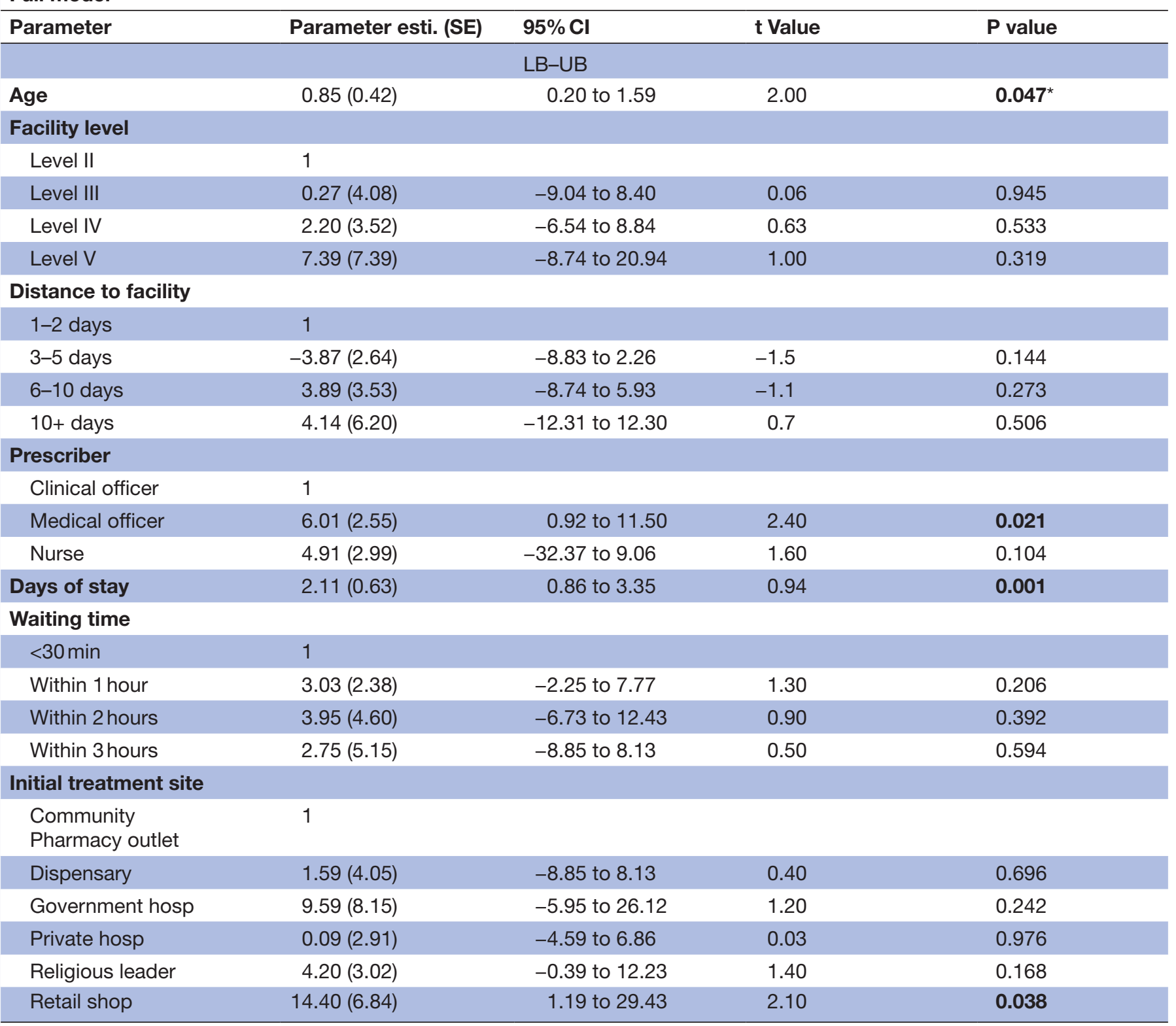

$\mathrm{R}^{2}=68 \%, \mathrm{R}^{2}$ - adjusted $=62 \%$.

*Bold $p$-values indicate significant association at $95 \%$ level of confidence 
Table 6 Reduced model for cost of treating paediatric malaria in Homa Bay County

Reduced model-after bootstrapping regression

\begin{tabular}{|c|c|c|c|c|}
\hline Parameter & Parameter est. (SE) & $95 \% \mathrm{Cl}$ & t Value & $P$ value \\
\hline \multicolumn{5}{|l|}{ Facility level } \\
\hline Level III & $3.36(3.19)$ & -2.97 to 9.69 & 1.1 & 0.294 \\
\hline Level IV & $5.87(2.61)$ & 0.70 to 11.04 & 2.3 & $0.026^{\star}$ \\
\hline Days of stay at facility & $2.38(0.58)$ & 1.23 to 3.53 & 4.1 & $<0.001$ \\
\hline \multicolumn{5}{|l|}{ Prescriber } \\
\hline Clinical officer & 1 & & & \\
\hline Medical officer & $6.98(4.29)$ & -1.51 to 15.47 & 2.40 & 0.106 \\
\hline
\end{tabular}

$\mathrm{R}^{2}=38 \%, \mathrm{R}^{2-}$ Adjusted $=33 \%$.

${ }^{*}$ Bold $p$-values indicate significant association at $95 \%$ level of significance

that indirect costs still impeded access to paediatric care irrespective of user fee abolition. ${ }^{14}$

One of the main contributors to total household costs was the value of time lost in the process of seeking care. This contributor was however measured subjectively from the verbal reports of respondents. An attempt to triangulate this information was made by way of asking the respondents to state their occupation. Most previous studies have not incorporated the cost of time lost due to care seeking in their costing models.

Compared with level II facilities, the total cost of care was more expensive by US $\$ 14$ (95\% CI $=3.25$ to 24.78$)$ in the level V facility. This increased total cost in higher level hospitals is in concurrence with the findings of a study in China. ${ }^{15}$ The level V facility was centrally located in the county and had healthcare providers with higher academic qualifications than those in lower level facilities. Before a patient is sent to such a facility, they were likely to have gone through lower level facilities. The cases referred to it are therefore more severe or need more specialised attention than those at lower level facilities. Similarly, before a patient comes to the higher level facility, they would have spent more on transport cost since it is centrally located in the county. They would also have spent more time caring for the ill child at the lower level facility prior to referral higher level. This may explain why the cost involved is at higher level facilities is higher compared with lower level facilities.

The average number of days spent in the facility was 2 days. For every additional day spent in the facility, the total cost of care increased by US $\$ 2.35$ (95\% CI $=1.23$ to 3.48 ). The number of days spent in the facility may also have been influenced by factors such the severity of illness at admission, the time taken before seeking care, quality of care and the bed capacity of the hospital. ${ }^{1617}$

Being prescribed medicines by a clinical officer led to the total cost being lower by US $\$ 7.5$ (95\% CI $=3.17$ to 11.76) compared being prescribed to by a medical officer. This may be because medical doctors tend to prescribe branded medicines more than their generic versions. ${ }^{18}$ However, in government health facilities where patients do not pay for consultation, this observation cannot be fully explained. Studies elsewhere have also reported that seeking care from medical doctors is more costly than lower cadre healthcare providers. ${ }^{19}$ Medical officers were more often found in higher level facilities which are few and centrally located hence accessing them attracted more transport and hotel costs. In many cases of paediatric malaria treatment, the main cost centres are often consultation, medicines, transport and hospitalisation with the most significant being the cost of medicines. ${ }^{20}$ In the contrary, from our findings, the greatest contributor to the total cost of care is the opportunity cost of productive time lost while caring for the sick child.

\section{CONCLUSION}

The Homa Bay County Referral Hospital (level V) is much more costly than the other lower level health facilities in the county indicating that the poorest who may not afford or access the specialised treatment offered thus may be financially barred from obtaining the superior paediatric malaria care. The top two drivers of patient borne cost of paediatric malaria treatment in Homa Bay County are being admitted at the county referral hospital and a medical officer prescribing the medication. Efforts aiming at reducing the cost of paediatric malaria treatment therefore need to focus on availing quality treatment at the lower level facilities through better trained and experienced staffing, performance monitoring and improved infrastructure. 


\section{Unanswered questions and future research}

From our findings, one of the greatest contributors to cost of treatment is being treated by a medical officer. It is not clear why this would be so especially in public health facilities where patients do not pay directly for consultation. This could be some form of indictment on the training and experience as well as training on treatment guidelines of medical staff in public service. There is therefore need for further research in other counties and regions to attempt to validate this finding.

Acknowledgements We wish to acknowledge the statistician, Dr Alex Mwaniki for his assistance with the conceptualisation of the study design and data analysis.

Contributors The conceptualisation and protocol development was done by all the authors. Data collection and analysis was done by MOK. MOK drafted the manuscript which was validated and edited by J0O and BKA. All authors gave final approval of the version to be published. All authors declare no financial nor personal relationship conflict of interest. All authors agree to be accountable for all aspects of the work in ensuring that questions related to the accuracy or integrity of any part of the work are appropriately investigated and resolved.

Funding The authors have not declared a specific grant for this research from any funding agency in the public, commercial or not-for-profit sectors.

Competing interests None declared.

Patient consent for publication Not required.

Ethics approval All principles pertaining ethical conduct of research with human subjects were adhered to in this study as embodied in the Declaration of Helsinki. Ethical approval was obtained from the Kenyatta National Hospital/University of Nairobi-Ethics and Review Committee (KNH-UON ERC Ref-P389/05/2016).

Provenance and peer review Not commissioned; externally peer reviewed.

Data availability statement Data are available in a public, open access repository. Extra data can be accessed via the Dryad data repository at http://datadryad.org/ with the doi: $10.5061 /$ dryad.prr4xgxhn.

Open access This is an open access article distributed in accordance with the Creative Commons Attribution Non Commercial (CC BY-NC 4.0) license, which permits others to distribute, remix, adapt, build upon this work non-commercially, and license their derivative works on different terms, provided the original work is properly cited, appropriate credit is given, any changes made indicated, and the use is non-commercial. See: http://creativecommons.org/licenses/by-nc/4.0/.

ORCID iD

Maurice Onditi Kodhiambo http://orcid.org/0000-0001-8800-4169

\section{REFERENCES}

1 Buigut S, Ettarh R, Amendah DD. Catastrophic health expenditure and its determinants in Kenya slum communities. Int J Equity Health 2015;14:46.
2 Ayieko P, Ogero M, Makone B, et al. Characteristics of admissions and variations in the use of basic investigations, treatments and outcomes in Kenyan hospitals within a new clinical information network. Arch Dis Child 2016;101:223-9.

3 World Health Organization. World malaria report 2015. Geneva: World Health Organization, 2015.

4 Onwujekwe O, Hanson K, Uzochukwu B, et al. Are malaria treatment expenditures catastrophic to different socio-economic and geographic groups and how do they cope with payment? A study in Southeast Nigeria. Trop Med Int Health 2010;15:18-25.

5 Sicuri E, Vieta A, Lindner L, et al. The economic costs of malaria in children in three sub-Saharan countries: Ghana, Tanzania and Kenya. Malar J 2013;12:307.

6 Sicuri E, Davy C, Marinelli M, et al. The economic cost to households of childhood malaria in Papua New Guinea: a focus on intra-country variation. Health Policy Plan 2012;27:339-47.

7 Barasa EW, Ayieko P, Cleary S, et al. Out-Of-Pocket costs for paediatric admissions in district hospitals in Kenya. Trop Med Int Health 2012;17:958-61.

8 . Available: http://datatopics.worldbank.org/world-developmentindicators/stories/the-classification-fcountries-by-income.html [Accessed 4 Oct 2018].

9 UN Inter-agency Group for Child Mortality Estimation. Kenya country summary, 2019.

10 Kenya National Bureau of Statistics (KNBS). Statistical Abstract 2015. Nairobi: KNBS, 2016.

11 Johnston KM, Lakzadeh P, Donato BMK, et al. Methods of sample size calculation in descriptive retrospective burden of illness studies. BMC Med Res Methodol 2019;19:9.

12 Comfort AB, van Dijk JH, Mharakurwa S, et al. Hospitalizations and costs incurred at the facility level after scale-up of malaria control: pre-post comparisons from two hospitals in Zambia. Am J Trop Med Hyg 2014;90:20-32.

13 Ayieko P, Akumu AO, Griffiths UK, et al. The economic burden of inpatient paediatric care in Kenya: household and provider costs for treatment of pneumonia, malaria and meningitis. Cost Eff Resour Alloc 2009;7:3.

14 Burke RM, Rebolledo PA, Embrey SR, et al. The burden of pediatric diarrhea: a cross-sectional study of incurred costs and perceptions of cost among Bolivian families. BMC Public Health 2013;13:708.

15 Xia S, Ma J-X, Wang D-Q, et al. Economic cost analysis of malaria case management at the household level during the malaria elimination phase in the people's Republic of China. Infect Dis Poverty 2016;5:50.

16 Kyaw SS, Drake T, Ruangveerayuth R, et al. Cost of treating inpatient falciparum malaria on the Thai-Myanmar border. Malar $J$ 2014;13:416.

17 Beogo I, Huang N, Drabo MK, et al. Malaria related care-seekingbehaviour and expenditures in urban settings: a household survey in Ouagadougou, Burkina Faso. Acta Trop 2016;160:78-85.

18 Adair RF, Holmgren LR. Do drug samples influence resident prescribing behavior? A randomized trial. Am J Med 2005;118:881-4.

19 Soremekun S, Kasteng F, Lingam R, et al. Variation in the quality and out-of-pocket cost of treatment for childhood malaria, diarrhoea, and pneumonia: community and facility based care in rural Uganda. PLoS One 2018;13:e0200543.

20 Nabyonga Orem J, Mugisha F, Okui AP, et al. Health care seeking patterns and determinants of out-of-pocket expenditure for malaria for the children under-five in Uganda. Malar J 2013;12:175. 